\title{
EXPERIMENTAL STUDY ON THE MECHANICAL AND DEFORMATION PROPERTIES OF PIPE AND SOIL IN RECTANGULAR PIPE JACKING CONSTRUCTION WITH CONTROLLABLE CEMENT GROUTING TECHNOLOGY
}

\author{
Jun Tang ${ }^{1,2}$ and Shengcai $\mathrm{Li}^{1}$
}

1. School of Civil Engineering, Huaqiao University, Xiamen 361021, China

2. Xiamen Xijiao Hard Science Industrial Technology Research Institute Co., Ltd, Xiamen,361006, China;sram8888@163.com

\begin{abstract}
Based on the utility tunnel project of Chengbei Road in Suzhou, the experimental study on the mechanical and deformation properties of pipe and soil in rectangular pipe jacking construction with controllable cement grouting drag reduction technology is carried out. Based on the monitoring and analysis of pipe and soil stress and deformation of pipe joints during pipe jacking, the relevant theoretical model is established and the finite element simulation is carried out to experimentally study and compare the stress and deformation of pipe and soil in rectangular pipe jacking construction with controllable cement grouting drag reduction technology. The results show that the controllable cement grouting drag reduction technology has a significant effect on the pipe and soil stress in rectangular pipe jacking, which reduces pipe-soil interaction forces effectively, and improves the overall safety of pipe jacking construction.
\end{abstract}

\section{KEYWORDS}

Controllable cement grouting technology, Cement grouting drag reduction, Rectangular pipe jacking, Mechanical behaviour Deformation property

\section{INTRODUCTION}

Since the introduction of rectangular pipe jacking construction technology in 1990s in China, due to the limitation of economy and technical maturity, there are few theories, experiments and engineering cases based on this technology. For the rectangular pipe jacking project with large crosssection and long distance [1], accurate pipe and soil stress analysis and effective slurry drag reduction measures will be an important basis to determine whether the project can be successfully implemented and improve the economy. According to the different principles adopted, the discussion and research on pipe and soil load can be divided into simplified analysis and calculation method, field measurement and model test method, etc [2].

In the simplified analysis and calculation method, the soil pressure on the pipe can be simplified as the vertical soil pressure on the upper part of the pipe joint, the horizontal soil pressure on the side of the pipe joint, the vertical subgrade reaction at the bottom of the pipe joint, and the passive subgrade resistance caused by pipe deformation [3]. The simplified analysis and calculation 
method simplify the pipe and soil load into the above four parts, and then carry out specific calculation of each part to solve the calculation question. However, this method cannot calculate the influence of different construction methods, segment stiffness and other factors on the magnitude and distribution of pipe and soil pressure and the calculated value is different from the field measured value [4].

Field measurement can reflect the comprehensive influence of various factors on soil pressure, and so many scholars attach great importance to the collection and analysis of field measurement data. The performance of lubrication for backfilling material is significant [5], and [6] conducted a field test study on a tunnel. The main beneficial mechanism of pipe jacking lubricants is the reduction of the local effective stress acting on the pipe through the generation and retention of excess pore water pressure in the soil near the interface. [7] also obtained similar research results. [8] measured the soil pressure distribution on the upper part of tunnel with gravel foundation. The research shows that the soil pressure acting on shallow tunnel can be based on the Terzaghi soil pressure and the load acting on deep tunnel is mainly the water pressure. [9] also obtained similar research results.

For the research on cement grouting drag reduction technology, [10] studied the formation process and disturbance effect of thixotropic slurry jacket during pipe jacking, showing the functions of filling, supporting, isolation and lubrication after slurry jacket injection and slurry film formation. [11] analyzed the thixotropic slurry mix proportion, and highly viscous bentonite slurry mixed with polymer was used to reduce the friction resistance. [12] carried out numerical analysis on the over excavation of deep pipe jacking construction, and the thickness and the distribution of the slurry at different pipe segments were calculated using the two - way travel time and the radar signal propagation velocity in the slurry.

The stress of pipe jacking in the construction process is very complex, and friction drag is the main part of all kinds of drag. [13] applied a model coupling finite element method and a displacement control method to estimate the required jacking force during rectangular pipe jacking, and analyzed the factors affecting the jacking force. [14] thought that different forms of slurry jacket had great influence on the effect of cement grouting drag reduction and investigated the causes of high deflection by the finite element method. The results showed that, various stiffening ribs are used in different deflection sections with grouting to decrease friction and lower the corresponding axial jacking force. [15] analyzed several construction cases of French national micro tunnel project, and the research results show that grouting cannot only reduce the dynamic friction during the jacking process, but also effectively reduce the additional friction caused by construction interval.

\section{ANALYSIS OF REAL-TIME MONITORING RESULTS IN THE TEST SECTION}

\section{Monitoring item and main content}

In this paper, the field monitoring of soil pipe contact pressure is carried out by installing pressure sensor on the surface of pipe joint, including soil pressure monitoring and pour water (slurry) pressure, to test the influence of controllable cement grouting drag reduction technology on soil pipe jacking.

\section{Layout of measuring point and observation method}

(1) Pipe joint design: the section size of pipe joint is $5.5 \mathrm{~m} \times 9.1 \mathrm{~m}$, the wall thickness is $650 \mathrm{~mm}$, the inner diameter is $4.2 \mathrm{~m} \times 7.8 \mathrm{~m}$, and the length and weight of single joint are $1.5 \mathrm{~m}$ and $66.8 \mathrm{t}$ respectively. The pipe joint is prefabricated with reinforced concrete, with strength of C50 and impermeability grade of P8. 


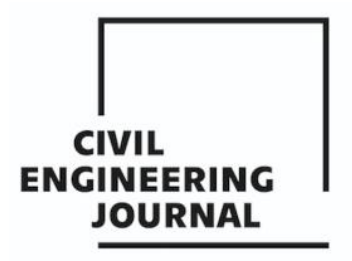

Article no. 11

THE CIVIL ENGINEERING JOURNAL 1-2021

(2) Monitored section: the total monitoring length of this pipe jacking project is $138 \mathrm{~m}$. Two pipe joints are selected as the monitored section. The distance between I\# pipe joint and the pipe jacking machine is $20 \mathrm{~m}$, and the distance between II\# pipe joint and I\# pipe joint is $30 \mathrm{~m}$. The jacking distance of I\# pipe joint is $118 \mathrm{~m}$, and the change of soil pressure in the whole pipe jacking construction can be observed. The jacking distance of II\# pipe joint is $88 \mathrm{~m}$, which can be used as the supplementary monitoring data of the monitored section of I\# pipe joint.

(3) Layout of measuring points: 11 soil pressure gauges are arranged at the monitored section of I\# pipe joint, 5 of which are located at the top of the monitored section, mainly monitoring the distribution of soil pressure at the section top and focusing on monitoring the change of soil pressure near the controllable cement grouting hole. Three soil pressure monitoring points are arranged on the right side of the section, evenly at the upper, middle and lower positions of the side wall of pipe joint, the left soil pressure monitoring points are arranged in the middle of the side wall of pipe joint, and the bottom monitoring points are evenly arranged at the bottom of the monitored section.

The specific layout of measuring points is shown in Figure 1.

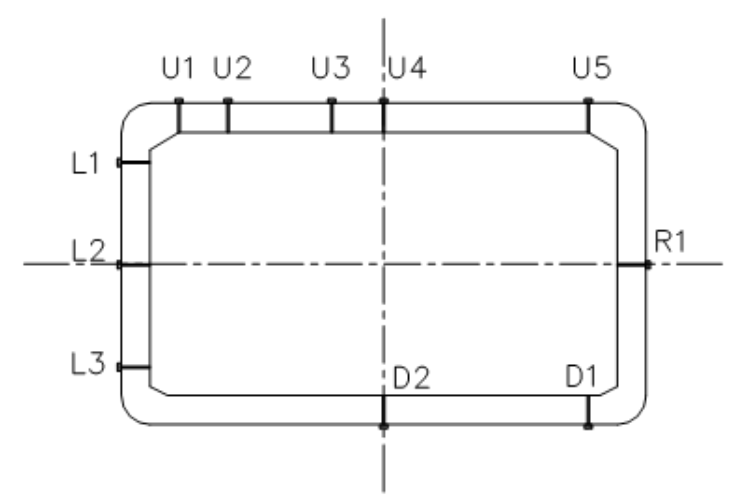

Fig.1 - Layout of measuring points for pipe joint

(4) Embedding of monitoring sensor:

(1) Soil pressure gauge

According to the spatial distribution, pipe jacking construction can be divided into three main parts: starting area, jacking area and receiving area, while the pressure monitoring only needs to be carried out in the jacking area. Since the starting area is often reinforced by bored piles, mixing piles and grouting, the monitored section should be protected when passing through the starting area.

(2) Pour water (slurry) pressure gauge

The pore water pressure gauge can be used to measure the pressure around the controllable cement grouting port. The pressure gauge sensor should be buried as close as possible to the controllable cement grouting port.

(3) Embedding of monitoring sensor:

The monitoring data of soil pressure gauge and slurry pressure sensor are recorded and stored by the acquisition module in the signal acquisition box through the signal line. The acquisition module has the ability to automatically acquire data according to the set time interval, and the acquisition time 


\section{ENGINEERINC} JOURNAL

mainly depends on the battery power and the capacity of storage card.

\section{Field monitoring results and analysis}

The field monitoring of the stress on I\# pipe joint structure took 3 months and 4990 groups of data were collected. In the process of monitoring, all sensors on I\# pipe joint worked normally, so the data of spare sensors on II\# pipe joint will not be discussed. In the process of controllable slurry injection, the orifice of the osmotic water pressure gauge was blocked and the slurry pressure could not be transmitted smoothly, so the osmotic water pressure data will not be discussed.

Analysis of monitoring data of pipe and soil contact pressure during pipe jacking construction

The data of I \# pipe section was monitored during the whole jacking process. According to different stages of construction, three main stages i.e. starting area, jacking area and receiving area will be discussed:

Starting area: The reinforcement thickness of the starting well is about $5 \mathrm{~m}$. Because the sensor is protected by a sleeve, although the data fluctuates, the pressure value is very small;

Jacking area: The jacking area is divided into jacking area with uniform geology and water rich soft soil jacking area.

(1) Jacking area with uniform geology

When the soil in front of the pipe jacking area was uniform and the settlement of the top soil was well controlled, the soil pressure monitoring data was relatively stable and had a certain correlation with the grouting pressure.

\section{(2) Water rich soft soil jacking area}

When the pipe jacking passed through the saturated soft soils area and the top may have large settlement or the ground had key protective buildings and structures, we performed high-pressure grouting around the pipe jacking. Under this condition, the monitoring data of soil pressure fluctuated greatly;

Receiving area: After the pipe jacking construction entered the receiving area, all monitoring data decreased.

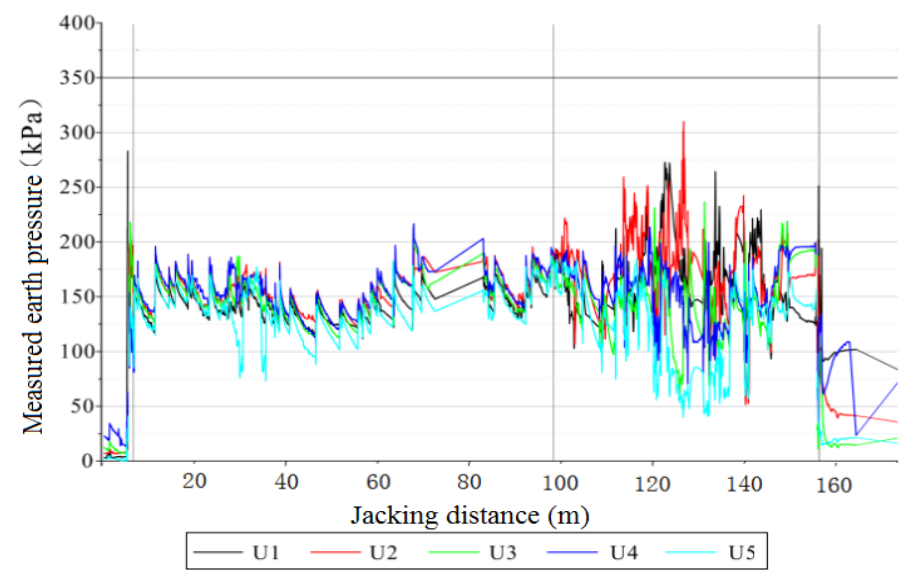

Fig. 2 - Time history curve of pressure change on top of the pipe 


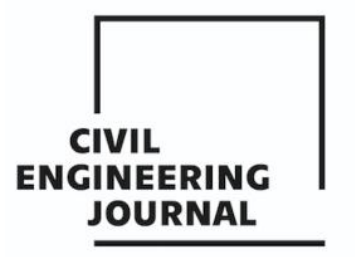

Article no. 11

THE CIVIL ENGINEERING JOURNAL 1-2021

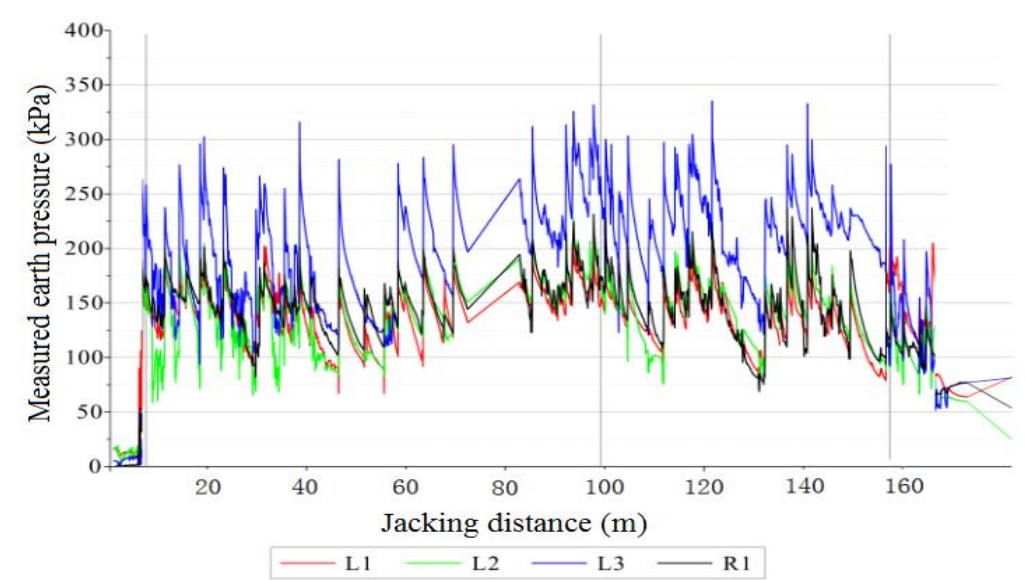

Fig.3 - Time history curve of pressure change on sidewall of the pipe

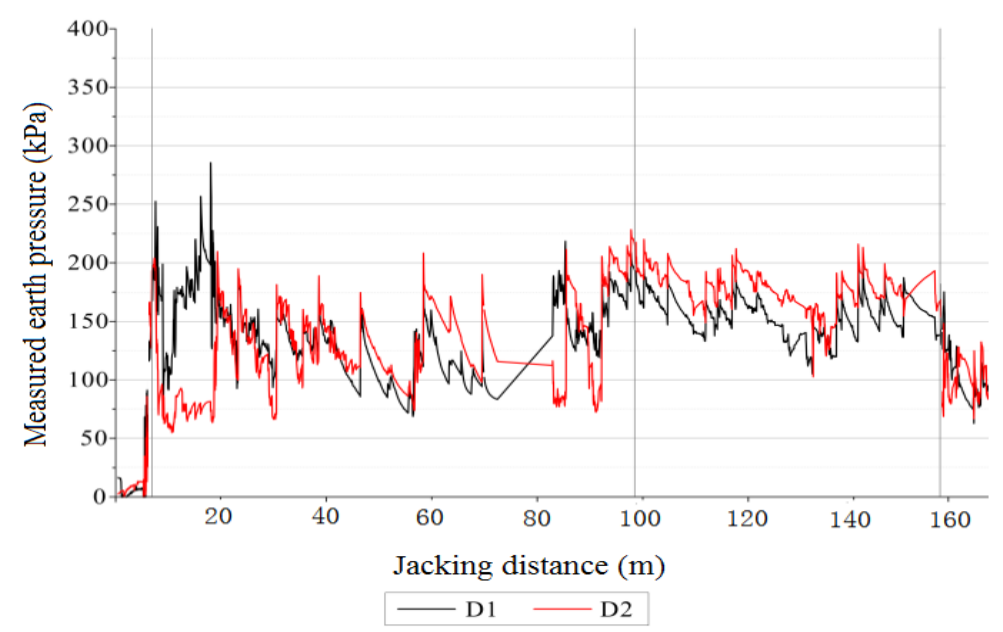

Fig. 4 - Time history curve of pressure change at the bottom of the pipe

\section{Starting reinforcement area}

Due to the sleeve protection measures adopted in the starting stage, the monitoring data of soil pressure gauge mainly reflects the pressure of the controllable slurry. In this stage, the pressure fluctuation was relatively small and the pressure value was at a relatively low level due to factors such as loose sealing and slurry loss. In order to ensure the stability of excavation surface and control the surrounding settlement, it is necessary to continuously inject controllable slurry in this stage.

(3) Jacking area with uniform geology

When jacking under uniform geological conditions, the soil pressure on the upper part of pipe section tended to be stable with a relatively consistent attenuation law. During the controllable slurry injection, the soil pressure increased rapidly. After grouting, due to factors such as the overall loss of slurry, the loss of slurry water and the change of slurry performance, the soil pressure detection data decreased slowly. Taking the monitoring values within $5 \mathrm{~m} \sim 65 \mathrm{~m}$ interval with regular data changes as 


\section{ENGINEERINC} JOURNAL

an example, the analysis is as follows:

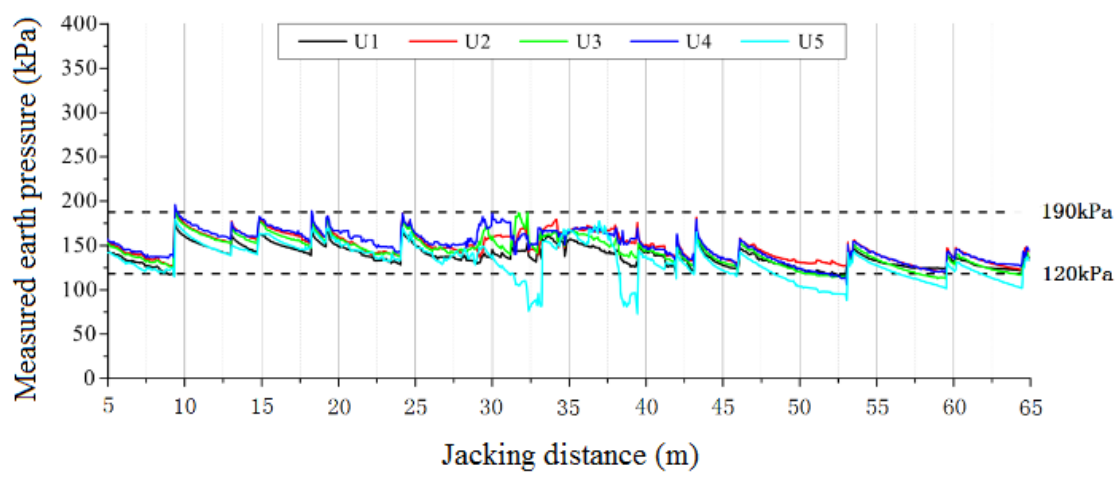

Fig.5 - Time history curve of pressure change on top of the pipe $(5 \mathrm{~m} \sim 65 \mathrm{~m})$

The monitoring values of soil pressure at the top of pipe joint are relatively consistent, mainly distributed between $120 \mathrm{kPa}$ and $190 \mathrm{kPa}$. The pressure change is mainly affected by controllable slurry construction. The steep rise and fall points of soil pressure value are all at controllable slurry injection points. Through analysis, it is mainly related to the technology of grouting hole opening and pressure boosting grouting, which needs to be paid more attention in the future construction.

The soil pressure values of the upper measuring points are basically the same, and the deviation between soil pressure values of each measuring point is basically maintained between $20 \mathrm{kPa}$ and $50 \mathrm{kPa}$, which shows that the controllable slurry performance and the selection of slurry grouting parameters in this stage are relatively reasonable.

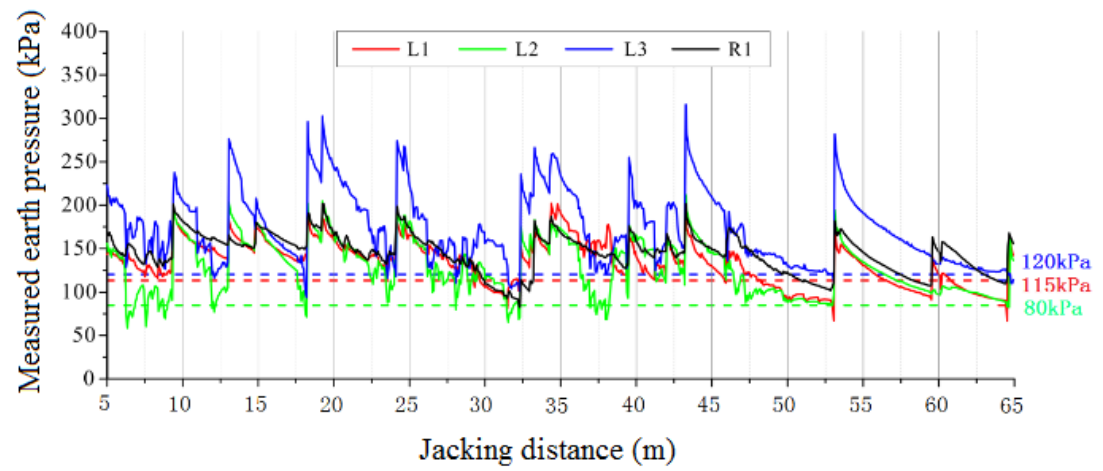

Fig.6 - Time history curve of pressure change on sidewall of the pipe (5m 65m)

The monitoring value of soil pressure on the side of pipe joint is consistent with the monitoring value on the top, but the change of L3 measuring point is more intense, and the influence of controllable slurry injection is obviously greater than other measuring points. The lower limit of the overall soil pressure of L3 measuring point is the highest, $120 \mathrm{kPa}$, and the maximum is $315 \mathrm{kPa}$, significantly higher than other measuring points; the lower limits of L2 and R1 are the lowest, both $80 \mathrm{kPa}$, and the maximum is about $180 \mathrm{kPa}$; the overall pressure of $\mathrm{L} 1$ is above $115 \mathrm{kPa}$. 


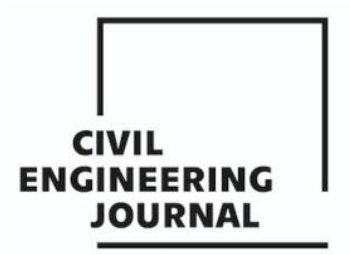

THE CIVIL ENGINEERING JOURNAL 1-2021

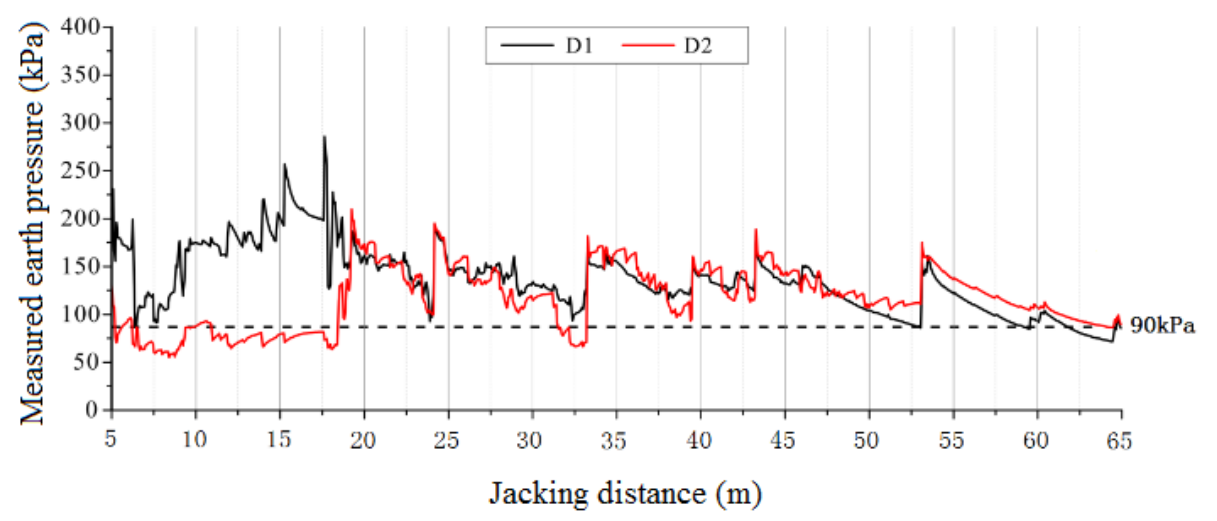

Fig. 7 - Time history curve of pressure change at the bottom of the pipe (5m $65 \mathrm{~m})$

The soil pressures of the lower two measuring points are between $5 \mathrm{~m}$ and $18 \mathrm{~m}$, with a large difference, but after $18 \mathrm{~m}$, the change trend of two points is very close, which may be due to the large difference in the bottom soil pressure monitoring values caused by the insufficient slurry filling at the initial stage of slurry injection. After jacking more than $18 \mathrm{~m}$ and three to five times of controllable cement injection, the space between D1 and D2 measuring points is gradually filled, and the pressure values of two points tend to be the same. The lower limit of the overall soil pressure values of the two points is about $90 \mathrm{kPa}$, and the maximum pressure value of D1 measuring point occurs at the position of $18 \mathrm{~m}$ jacking pipe, which is about $300 \mathrm{kPa}$.

Water rich soft soil jacking area

The soil pressure value of upper monitoring point is significantly affected by controllable slurry injection, and shows irregular changes with grouting, and the overall lower limit of detection values is about $110 \mathrm{kPa}$. The highest and lowest monitoring values appear at U2 and U5 measuring points respectively, about $310 \mathrm{kPa}$ and $45 \mathrm{kPa}$.

Compared with the area with uniform geology, the variation law of the lateral soil pressure and the bottom soil pressure in the saturated soft soils area is consistent to some extent, but the influence of lateral soil pressure value is limited. The maximum value of lateral soil pressure is $330 \mathrm{kPa}$ at $\mathrm{L} 3$ measuring point and the minimum value is $50 \mathrm{kPa}$ at $\mathrm{L} 2$ measuring point; the overall lower limits of $\mathrm{L} 1$, L2 and L3 measuring points are about $80 \mathrm{kPa}, 100 \mathrm{kPa}$ and $120 \mathrm{kPa}$ respectively. The maximum value of bottom soil pressure appears at point $\mathrm{D} 2$, which is $230 \mathrm{kPa}$, and the minimum value is also at point $\mathrm{D} 2$, which is $45 \mathrm{kPa}$, and the overall lower limit value is about $100 \mathrm{kPa}$.

According to the analysis of monitoring results, the injection of controllable cement for drag reduction has the greatest impact on the upper soil pressure measuring point, followed by the bottom soil pressure, while the side soil pressure of pipe joint is basically not affected. In the process of design and construction, we paid more attention to the most unfavorable working condition and stress state, so the following will focus on the uniform geology jacking area. 3

\section{ANALYSIS OF SPATIAL PRESSURE DISTRIBUTION OF PIPE AND SOIL}

For rectangular pipe joint, the pipe joint can be simplified as a closed frame structure for calculation. The moment distribution of frame structure is the focus of design and construction work. In the injection of controllable cement for drag reduction, the soil pressure in the upper part of frame 


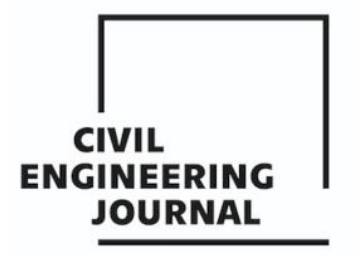

Article no. 11

THE CIVIL ENGINEERING JOURNAL 1-2021

structure is the largest, followed by the bottom soil pressure, and the soil pressure at the side is the smallest, which is most unfavourable to the frame structure.

The above-mentioned load form generally appears in the process of controllable slurry injection. According to the above analysis process, the load on the top, side and bottom of pipe joint is simplified now to establish a simplified pipe and soil model for jacking section with uniform geology, which is convenient for further computer modelling and finite element analysis.

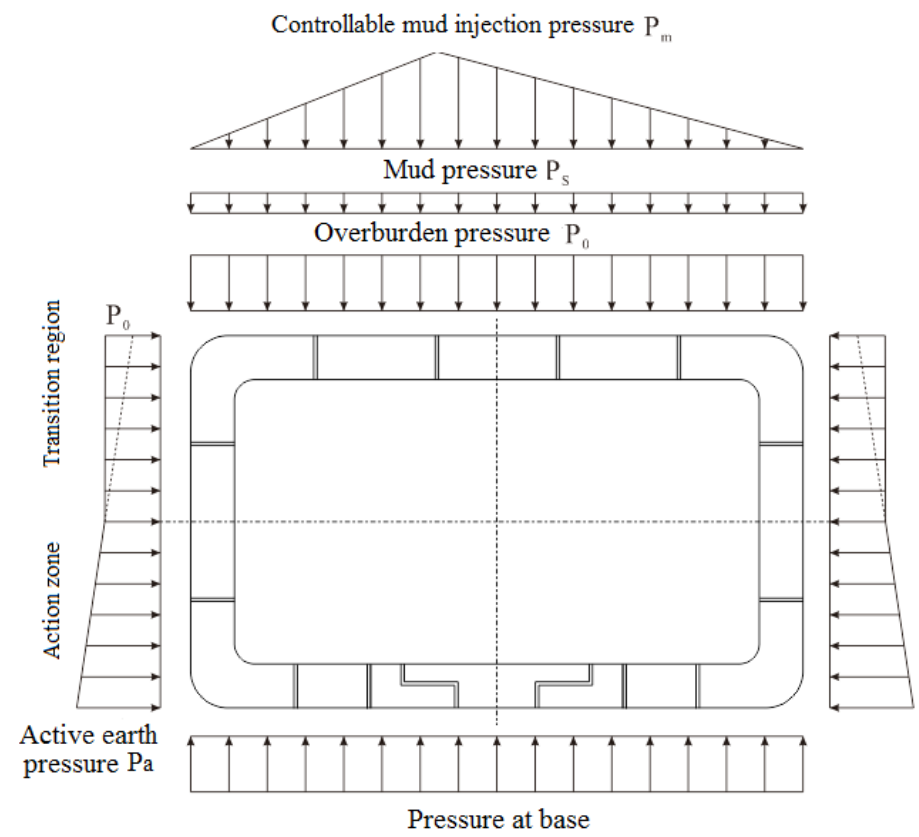

Fig. 8 - Pressure model for pipe and soil

The upper soil pressure includes covering soil pressure $\mathrm{P}_{0}$, slurry pressure $\mathrm{P}_{\mathrm{s}}$ and controllable slurry injection pressure $P_{m}$, in which the soil pressure $P_{0}$ is the soil pressure from the top plate of pipe joint to the ground; slurry pressure $P_{S}$ is the additional pressure caused by the slurry layer outside the pipe joint, which is assumed to be uniform load; slurry injection has a certain fluidity, which can be assumed to be triangle load, and the maximum value appears at the position corresponding to the pipe joint grouting hole. Here, U3 grouting hole is taken as an example.

The lateral soil pressure is divided into two regions, the upper transition region and the lower active soil pressure region. The upper transition region simplifies the linear change of soil pressure distribution form, the upper part of pipe joint is consistent with the covering soil pressure $P_{0}$, and the active soil pressure value of the middle of pipe joint is used. The lower active soil pressure region is from the middle of pipe joint to the bottom, and the active soil pressure in this region is used as Eq. 1

$$
p_{a}=\left[\gamma\left(Z-Z_{w}\right)+\gamma^{\prime}\left(Z_{w}+h\right)\right] K_{a}+\gamma_{w}\left(Z_{w}+h\right)
$$

Where: $\gamma$ is the natural gravity of soil, and the saturated gravity when below the groundwater level; $\gamma^{\prime}$ is the effective gravity of soil (floating gravity), $\gamma^{\prime}=\gamma-10\left(\mathrm{kN} / \mathrm{m}^{3}\right), \gamma_{w}$ is the gravity of water, $10 \mathrm{kN} / \mathrm{m}^{3}$. 
Tab. 1 - Main properties of the soil

\begin{tabular}{|l|l|l|l|l|l|}
\hline \multirow{2}{*}{ Stratum } & \multirow{2}{*}{ Stratum name } & Stratum thickness & Natural density & \multicolumn{2}{|l|}{ Consolidated quick shear } \\
\cline { 3 - 6 } & & $\mathrm{h}$ & $\rho$ & $\mathrm{C}_{\mathrm{q}}$ & $\varphi_{\mathrm{q}}$ \\
\cline { 3 - 6 } & & $(\mathrm{m})$ & $\left(\mathrm{g} / \mathrm{cm}^{3}\right)$ & $\mathrm{kPa}$ & ${ }^{3}$ \\
\hline$(1)-5$ & Plain fill & 3.66 & 1.92 & -- & -- \\
\hline$(4)$ & Clay & 2 & 1.99 & 47.9 & 15.3 \\
\hline$(5)$ & Silty clay with silt & 1.3 & 1.92 & 26.7 & 19 \\
\hline$(6)-1$ & Clayey silt with sand & 4.4 & 1.91 & 5.6 & 28.4 \\
\hline$(6)-2$ & Silty sand & 4 & 1.94 & 3.9 & 32.9 \\
\hline$(7)$ & Silty clay & 5.7 & 1.93 & 30 & 17.4 \\
\hline
\end{tabular}

Put the data in Table 1 into the above formula to calculate the soil pressure value of each point, as shown in Figure 9.

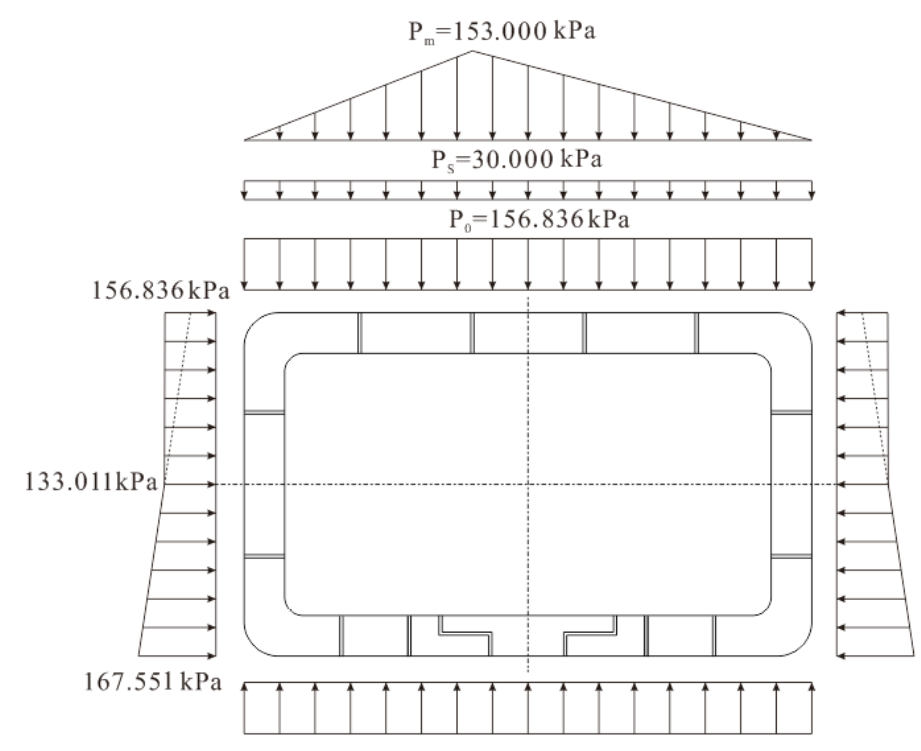

Fig.9 - Distribution hypothesis of the most unfavourable load

In this simplified model, the theoretical values of pressure at each measuring point are compared with the measured values, as shown in Table 2. It can be seen that the relative theoretical value of the model is conservative. At the same time, there is a good correlation between the measured value and the theoretical value, which can be used after appropriate reduction.

Table 2 Comparison between theoretical value and measured value of soil pressure

\begin{tabular}{|c|c|c|c|c|c|c|c|c|c|}
\hline \multicolumn{2}{|c|}{ Location } & U1 & U2 & U3 & U4 & U5 & L1 & L2 & L3 \\
\hline \multirow{2}{*}{$\begin{array}{c}\text { Soil } \\
\text { pressure } \\
(\mathrm{kPa})\end{array}$} & $\begin{array}{c}\text { Theoretical } \\
\text { model }\end{array}$ & 228.834 & 264.365 & 339.8783 & 314.643 & 214.873 & 149.012 & 133.034 & 167.625 \\
\hline & $\begin{array}{c}\text { Measured } \\
\text { value }\end{array}$ & 188.6 & 201.8 & 275.2 & 239.7 & 107.2 & 111.4 & 78.1 & 124.7 \\
\hline
\end{tabular}




\section{FINITE ELEMENT SIMULATION}

Internal force distribution modelling and calculation process

(1) Modelling: When building cell model, quadrilateral cell is selected for soil cell, pipe joint cell and slurry cell.

(2) Parameter setting: Linear elastic model is adopted for pipe joint, and physical parameters of material refer to $\mathrm{C} 50$ concrete parameters; classical Mohr-Coulomb elastic-plastic model with simple calculation is adopted for soil material, and measured parameters of detail geological survey are selected for physical parameters; elastic model is adopted for controllable slurry material, and laboratory test values (density $1200 \mathrm{~kg} / \mathrm{m}^{3}$, elastic modulus $1.5 \mathrm{~m}$, breaking ratio 0.4 ) of controllable slurry are selected for material properties

(3) Boundary condition: The soil cell limits the displacement in $\mathrm{x}$ and $\mathrm{y}$ directions.

(4) Definition of interaction: For the contact between pipe joint and soil, controllable slurry layer and pipe joint, the tangential characteristic is calculated by penalty function, and the friction coefficient is 0.3 . The normal characteristic is simulated by hard contact.

(5) Divide the cell grid as a whole.

(6) Loading: Use the concept of cell life and death in ABAQUS to simulate pipe jacking construction.

(7) Calculate and obtain the corresponding pipe joint and soil stress distribution through postprocessing.

When the grouting pressure is set to $0 \mathrm{kPa}, 100 \mathrm{kPa}, 130 \mathrm{kPa}, 150 \mathrm{kPa}$ and $180 \mathrm{kPa}$ respectively, the Mises stress nephogram of soil and pipe joint is shown in Fig. 10-14. With the increase of grouting pressure, Mises stress increases gradually, and the same stress distribution trend is shown in three cases. According to the stress nephogram of the soil, the maximum stress appears at the bottom corner of the excavation area, indicating that it is a weak stress area. More attention should be paid in the actual construction, and measures such as squeezing thick slurry can be taken in the dangerous area to improve the bearing capacity of pipe joint to the soil.
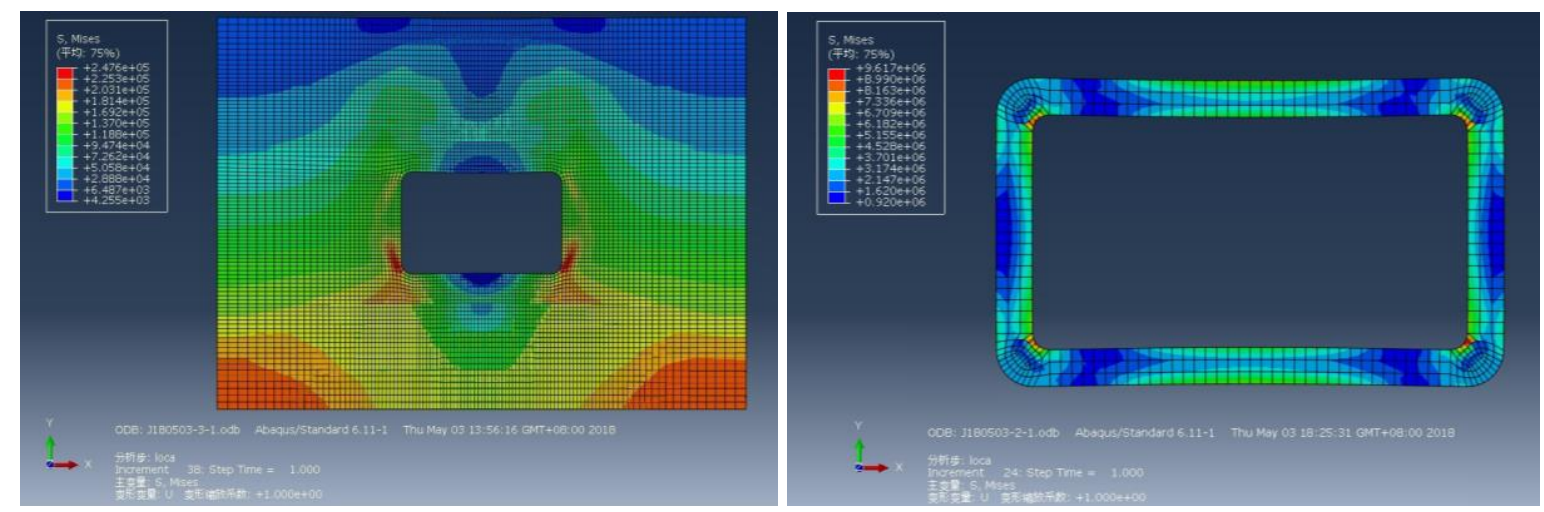

Fig. 10 - Mises stress nephogram of soil and pipe under $\mathrm{OkPa}$ 


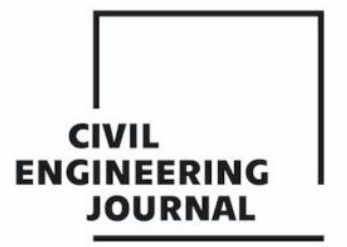

Article no. 11

THE CIVIL ENGINEERING JOURNAL 1-2021

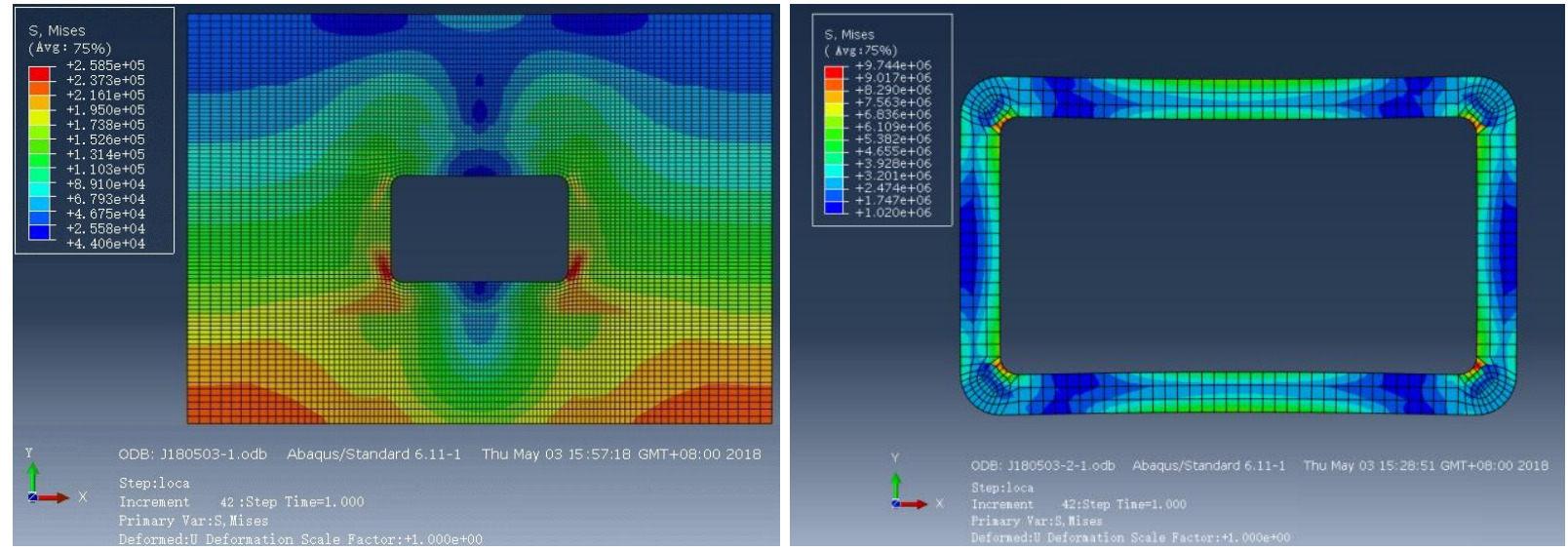

Fig.11 - Mises stress nephogram of soil and pipe under 100kPa
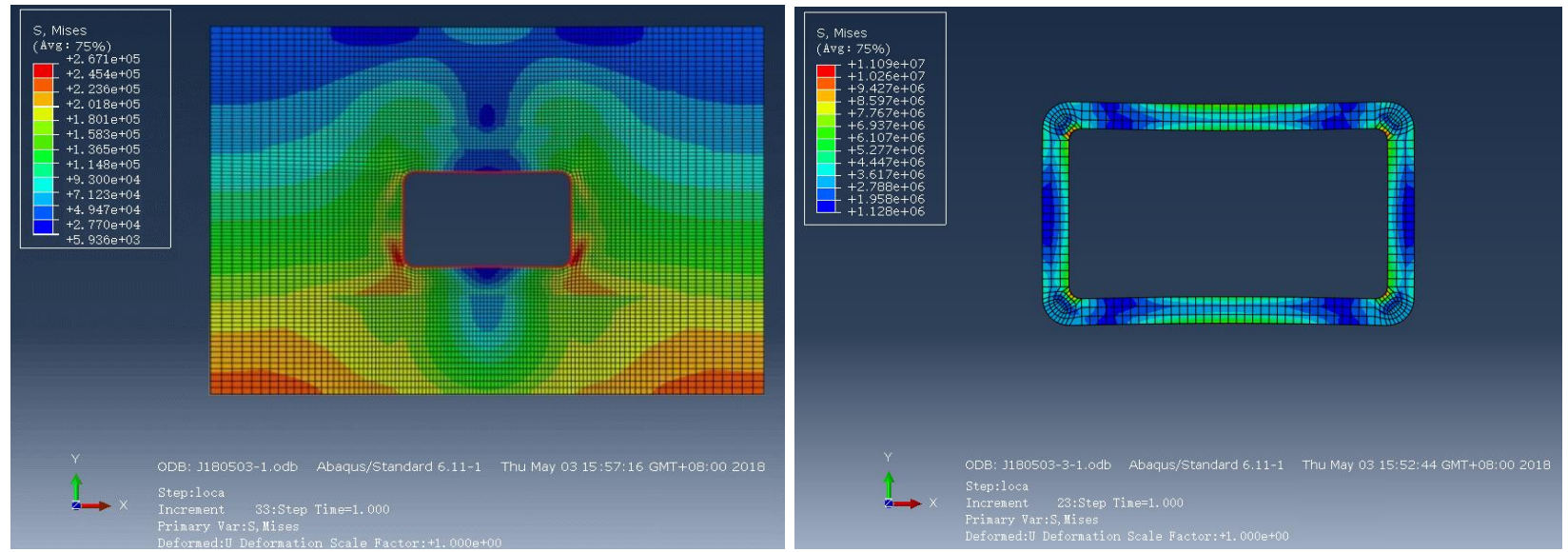

Fig. 12 - Mises stress nephogram of soil and pipe under $130 \mathrm{kPa}$

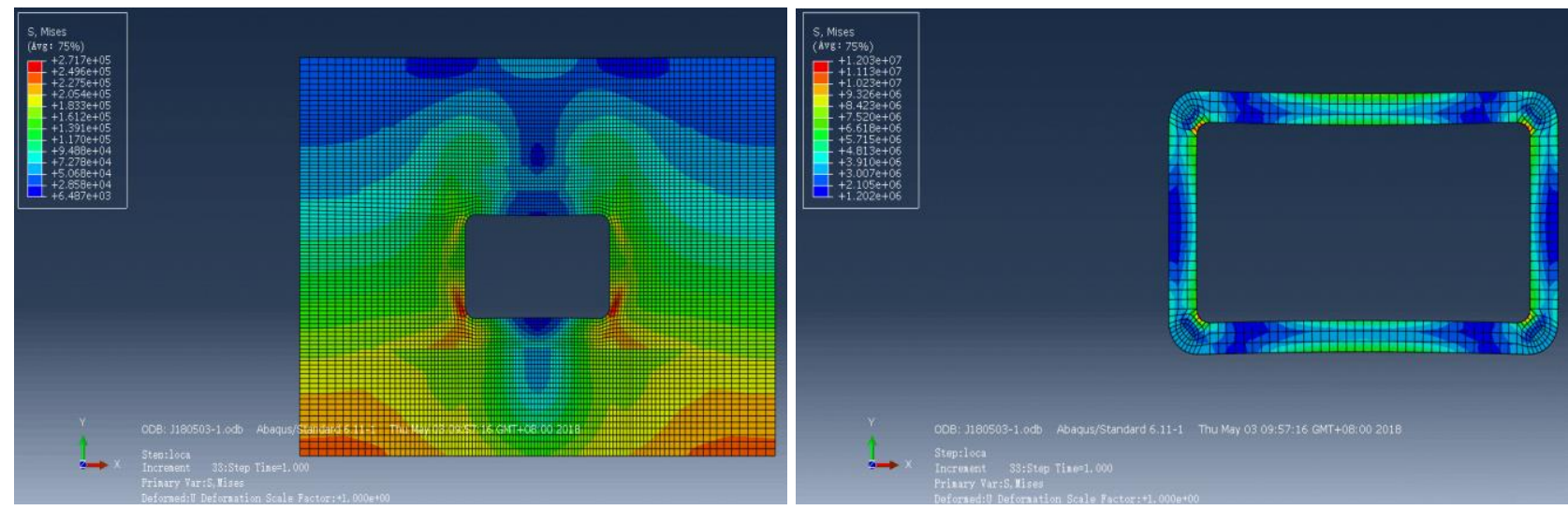

Fig. 13 - Mises stress nephogram of soil and pipe under $150 \mathrm{kPa}$ 


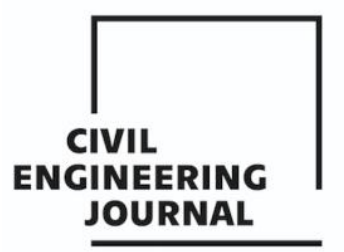

Article no. 11

THE CIVIL ENGINEERING JOURNAL 1-2021

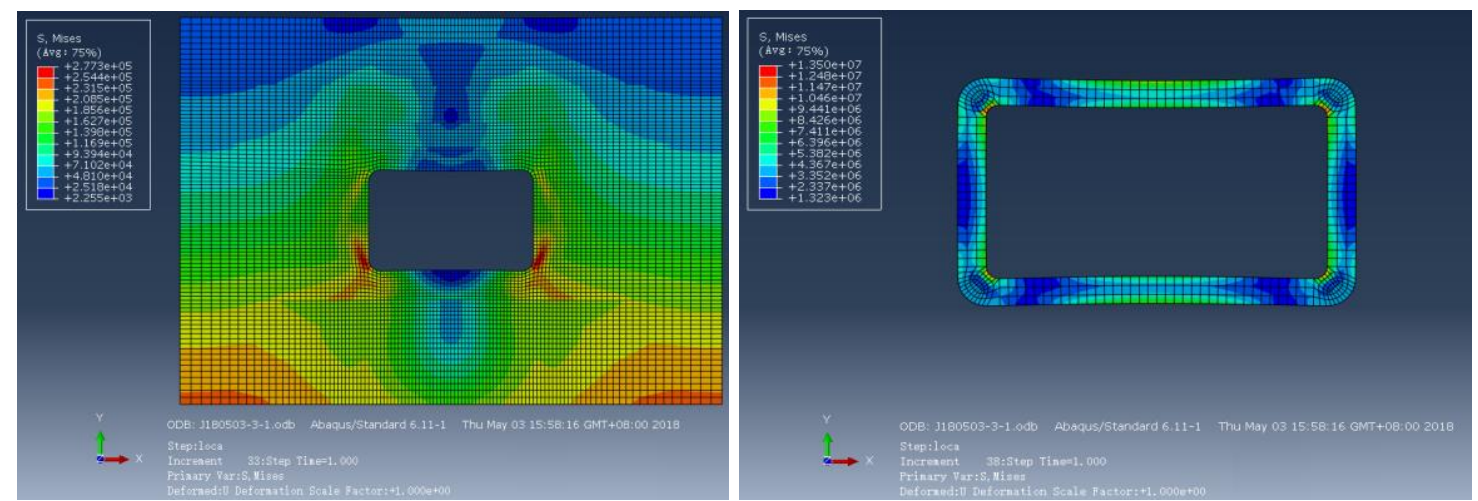

Fig. 14 - Mises stress nephogram of soil and pipe under $180 \mathrm{kPa}$

(2) Calculation results of pipe joint deformation

Figure $15 \sim$ Figure 18 show the pipe deformation nephogram during pipe jacking construction under different grouting pressure. It can be seen from the Figures that the soil on the side of pipe joint is highly squeezed, the compression area is basically symmetrical on both sides of the pipe centre, the soil pressure zone is circularly expanded, and the maximum horizontal displacement occurs in the centre of the pipeline. With the increase of grouting pressure, the maximum deformation of pipe joint increases nonlinearly, but the change range is small. The horizontal deformation on both sides of the pipeline indicates that the grouting layer between the pipeline and the soil is also squeezed. At the completion of pipe jacking construction, the soil pressures at the pipe top and the pipe bottom decrease. The decrease of soil pressure at the pipe top is due to the increase of lateral soil pressure under the action of soil arch, and the pipe section loses its original state and slightly deforms under the action of vertical soil pressure. There is a harmonious deformation relationship between the deformed pipe and the squeezed soil.

\section{(3) Analysis of finite element calculation results}

In the process of pipe jacking construction, with the passing of pipe jacking machine head, due to the difference between the outer diameter of segment and machine head, it is difficult to completely recover the initial state of soil by grouting alone and easy to cause soil disturbance and ground settlement spreading from the top of pipeline axis to the ground in a ring. With the construction of pipe jacking, the disturbed soil is consolidated by drainage, and some consolidation settlement is produced until the surface settlement is stable. In a certain range, with the increase of grouting pressure, the maximum settlement of surface soil decreases nonlinearly. 


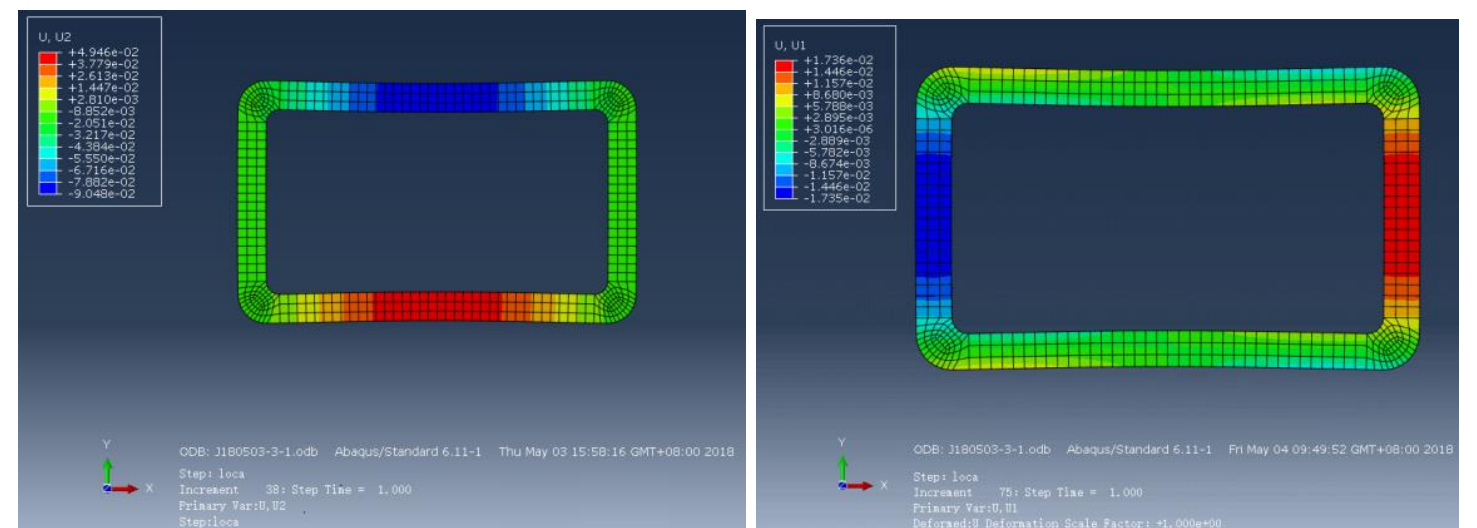

Fig. 15 - Pipe deformation under 100kPa pressure (vertical and horizontal)

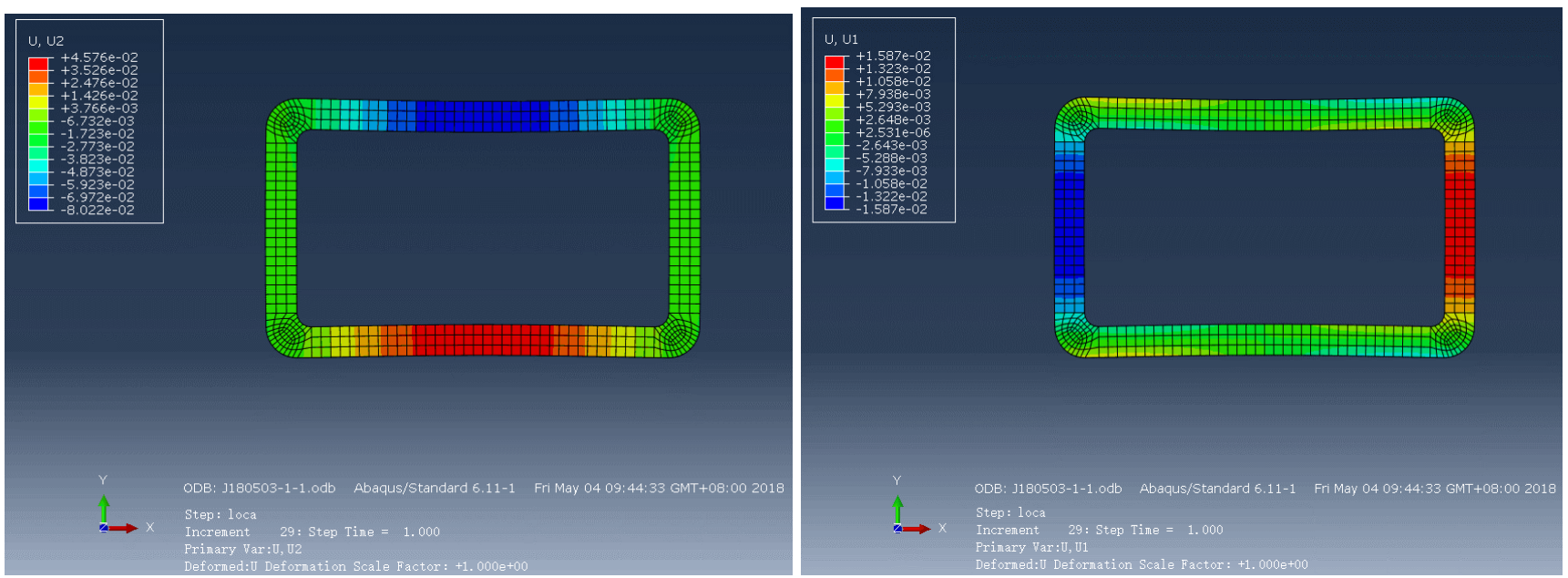

Fig. 16- Pipe deformation under 130kPa pressure (vertical and horizontal)
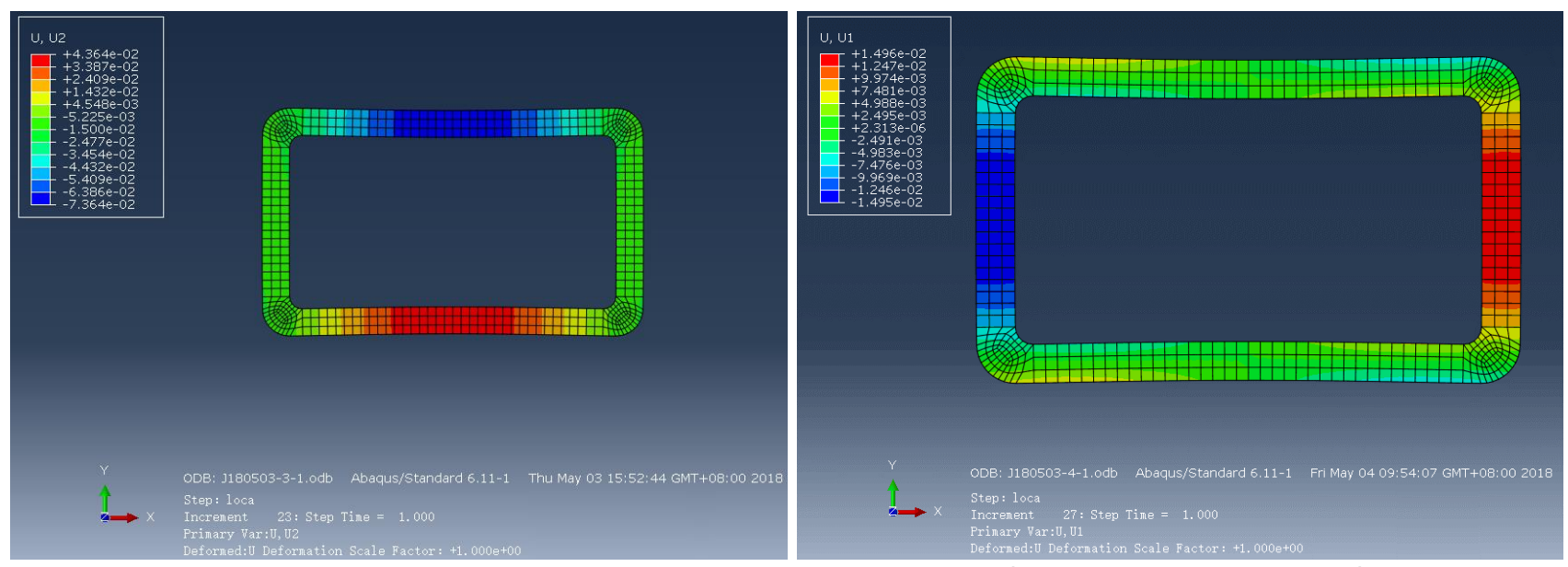

Fig. 17 - Pipe deformation under 150kPa pressure (vertical and horizontal) 


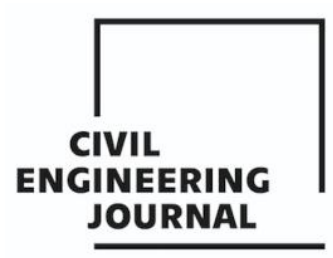

Article no. 11

THE CIVIL ENGINEERING JOURNAL 1-2021
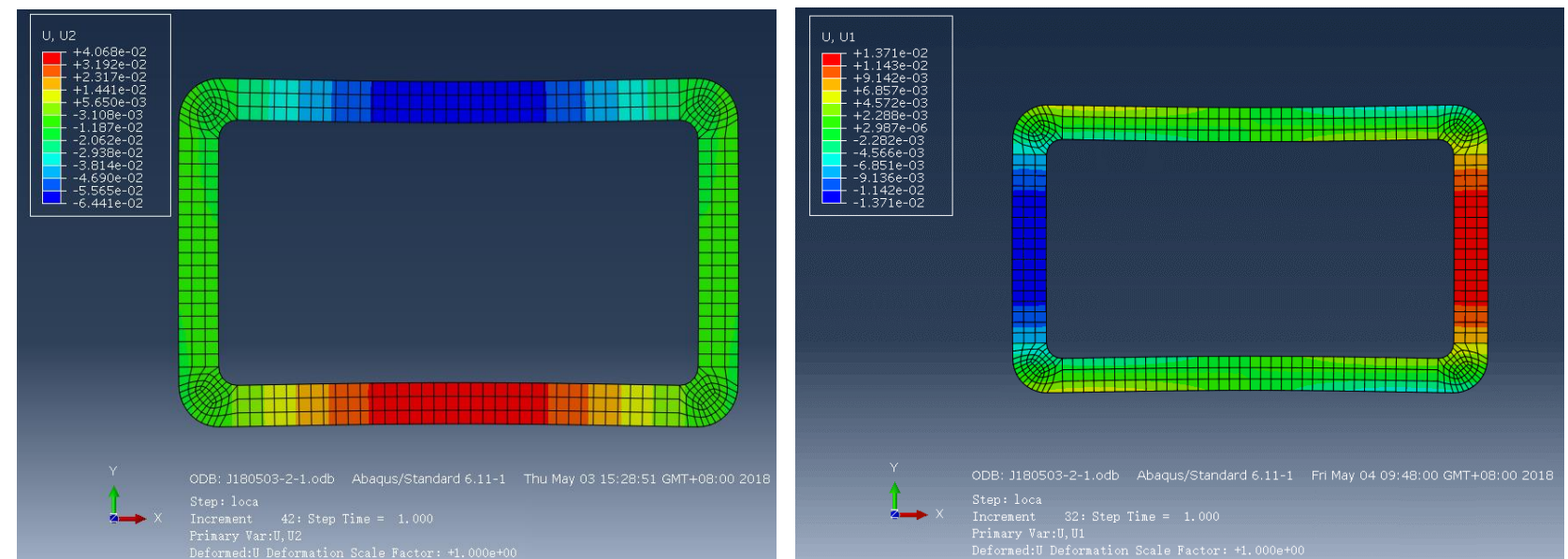

Fig.18 - Pipe deformation under 180kPa pressure (vertical and horizontal)

\section{CONCLUSION}

According to the field monitoring results, combined with theoretical analysis and numerical simulation, the variation of soil pressure and the internal force distribution of pipe joint in the construction of rectangular pipe jacking with controllable cement drag reduction technology are studied. The main conclusions are as follows:

(1) According to the change of soil pressure, the load mode of rectangular pipe jacking can be divided into the starting area, jacking area and receiving area: it tends to be 0 when the soil pressure in the starting area is stable, because the steel sleeve protection measures are adopted; the jacking area with uniform geology is only affected by the fluctuation of grouting pressure; the water rich soft soil jacking area is partially affected by controllable cement injection for drag reduction and slurry jacket, and the maximum pressure is $345.08 \mathrm{kPa}$; and the pressure in the receiving area changes irregularly.

(2) The distribution and volume of the contact pressure of pipe and soil are significantly affected by grouting. The grouting pressure and volume in the water rich soft soil jacking area are large, which is very easy to build the pressure locally, resulting in the sudden increase of pressure at the adjacent measuring points and the abnormal decrease of pressure at the remote measuring points. Therefore, in the actual construction process, special attention should be paid to the control of grouting pressure and grouting volume, so as to avoid building the pressure and pressure mutation.

(3) Through numerical modelling and analysis, it is difficult to completely recover the initial state of soil by grouting alone and easy to cause soil disturbance and ground settlement spreading from the top of pipeline axis to the ground in a ring. From the simulation results, it can be found that when the grouting pressure is controlled at 1.1-1.2 times of the covering soil weight, the soil displacement caused by grouting pressure can be controlled at an ideal level.

(4) The experimental results show that the steel sleeve design can effectively protect the soil pressure gauge when the sensor passes through the reinforcement area of the tunnel portal, which provides a reference for similar engineering measurement. 


\section{REFERENCES}

[1] Wen, K. ; Shimada, H. ; Zeng, W. ; Sasaoka, T. ; Qian, D. 2020: Frictional analysis of pipe-slurry-soil interaction and jacking force prediction of rectangular pipe jacking. European Journal of Environmental and Civil Engineering, vol. 24, no. 6, pp. 814-832.

[2] Md. Tareq Hossain Khondoker; Yaolin Yi; Alireza Bayat. 2016: Comparison of different methods for normal stress calculation during pipe jacking/microtunneling. International Journal of Geotechnical Engineering, vol. 10 , no. 4, pp. 366-376.

[3] Takeru ARIIZUMI; Masahiro YOSHIMOTO. 2000: RESULT AND ANALYSIS ON SITE MEASUREMENT OF LOAD ACTING ON SHIELD TUNNEL (3RD REPORT). Japan Society of Civil Engineers, vol. 10, pp. 275280.

[4] Raymond L. Sterling. 2020: Developments and research directions in pipe jacking and microtunneling. JOURNALS: Underground Space, vol. 5, no. 1, pp. 1-19.

[5] Kazuki Maehara; Takashi Sasaoka; Akihiro Hamanaka; et al. 2019: Effect of Fatty Acids Addition into Backfilling Material in Over-cutting Area on Improvement of Lubrication Performance for Pipe Jacking;;Background:;;Methods:;;Conclusion.The Open Civil Engineering Journal, vol. 13, pp. 281-287.

[6] Ciaran C. Reilly; Trevor L.L. Orr. 2017: Physical modelling of the effect of lubricants in pipe jacking. Tunnelling and Underground Space Technology incorporating Trenchless Technology Research, vol. 63, pp. 4453.

[7] K. Górski; R. L. Ignatowicz. 2016: EFFORT OF STEEL PIPE JACKING IN TERMS OF IMPERFECTION PIPES AND HETEROGENEITY OF GROUND. Nauka ta Progres Transportu, vol. 63, no. 3, pp. 171-180.

[8] Mashimo H; Ishimura T. 2003: Evaluation of the load on shield tunnel lining in gravel. JOURNALS: Tunnelling and Underground Space Technology incorporating Trenchless Technology Research, vol. 18, no. 23, pp.171-180.

[9] Sun Y; Wu F; Sun W; et al. 2019: Two Underground Pedestrian Passages Using Pipe Jacking: Case Study. Journal of Geotechnical \& Geoenvironmental Engineering, vol. 145, no. 2.

[10] Xinbo Ji; Wen Zhao; Pengpeng Ni; et al. 2019: A method to estimate the jacking force for pipe jacking in sandy soils. Tunnelling and Underground Space Technology incorporating Trenchless Technology Research, vol. 90, pp. 119-130.

[11] Jianfeng Wang; Kang Wang; Tao Zhang; Shuai Wang. 2018: Key aspects of a DN4000 steel pipe jacking project in China: A case study of a water pipeline in the Shanghai Huangpu River. Tunnelling and Underground Space Technology incorporating Trenchless Technology Research, vol. 72, pp. 323-332.

[12] Yonghui Zhao; Jiansheng Wu; Xiongyao Xie; Kunwei Feng; Chenchao Zeng. 2016: Ground- penetrating radar measurement of the distribution of thixotropic slurry behind large- diameter segments in long- distance pipe- jacking construction. Near Surface Geophysics, vol. 14, no. 2, pp.171-181.

[13] J. Yen; K. Shou. 2015: Numerical simulation for the estimation the jacking force of pipe jacking. Tunnelling and Underground Space Technology incorporating Trenchless Technology Research, vol. 49, pp.218-229.

[14] Liang Zhen; Jin-Jian Chen; Pizhong Qiao; Jian-Hua Wang. 2014: Analysis and remedial treatment of a steel pipe-jacking accident in complex underground environment. Engineering Structures, vol. 59, pp.210-219.

[15] A.-L Pellet-Beaucour; R Kastner. 2002: Experimental and analytical study of friction forces during microtunneling operations. Tunnelling and Underground Space Technology incorporating Trenchless Technology Research, vol. 17, no. 1, pp.83-97. 